\title{
A New Method of Removing Inclusions in Molten Steel by Injecting Gas from the Shroud
}

\author{
Qiao Ying ZHANG, ${ }^{1)}$ Li Tao WANG ${ }^{21}$ and Zhi Rong $X^{31}$ \\ 1) School of Metallurgical and Ecological Engineering, University of Science and Technology Beijing, No. 30 Xue yuan road, \\ Haidian District, Beijing 100083, China. E-mail: Zhqy19761013@163.com \\ 2) Shougang Research Institute of Technology, Shijingshan District, Beijing 100041, China. \\ 3) Tangshan Iron and Steel Corp., No. 9 Binhe road, Tangshan 063016, China.
}

(Received on January 4, 2006; accepted on May 16, 2006)

\begin{abstract}
A technology of removing inclusions in molten steel by injecting gas from the shroud has been analyzed and studied by method of mathematical model and water model. Study of position of injecting gas, flow rate of gas and gas nozzle size on the generated bubble size and distribution at the shroud has been investigated; the relationship between blowing parameters and inclusion removal efficiency has been analyzed in order to optimize the blowing parameters. The results show that the stronger turbulent vortex at the enlarged part in the shroud favors fine bubbles generation and uniform distribution; fine bubbles in diameter of 0.3 to $0.5 \mathrm{~mm}$ can be generated in the shroud and tundish by controlling flow rate of gas. The superfluous gas makes bubble size largen sharply. The nozzle size has some effect on bubbles size and distribution; the larger nozzle size goes against fine bubbles generation. So the optimum gas injected position is located at the enlarged part in the shroud. The resonable flow rate of gas and nozzle size would greatly improve inclusion removal efficiency.
\end{abstract}

KEY WORDS: tundish; ladle shroud; fine bubble; inclusion; mathematical model; water model.

\section{Introduction}

Inclusions in the molten steel can be efficiently removed by injecting inert gas because the generated bubbles lead to not only stirring molten steel but also has a subsidiary function of adhering inclusions particles which are then floated to the surface of the molten steel.

The removal of inclusions in the molten steel includes two approaches: one is to promote large inclusions flotation by Stokes flotation; another is to remove small inclusions by bubbles adhesion. The larger inclusions particles can be removed mainly by the former, while the smaller inclusions particles can be removed mainly by the later due to the smaller flotation velocity. Further reducing inclusion in molten steel becomes one of the main objects in steelmaking process; particularly the small size inclusions are necessary to reduce to extremely low levels. So it is essential to promote the small size inclusion removal by the second approach. Researchers have analyzed the removal behavior of inclusion particles and bubbles from liquid steel. ${ }^{1-9)}$ The results show that the small size bubble is beneficial to remove inclusion by adhesion. But the bubbles generated by the gas injection with porous plug, tuyeres and lances are typically 10 to $20 \mathrm{~mm}$ in diameter. ${ }^{7}$ The function of the bulky bubbles for removing inclusion by adhesion is neglectable. Zhang et al. have developed a method of generating fine bubbles by injecting gas at the shroud from a ladle to a tundish in a continuous casting system, ${ }^{1)}$ and the primary water model experiment have carried through. In this technology, the injected gas can be split into fine bubbles by the molten steel with stronger turbulent intensity, which can collide with inclusions particles and the floated to surface of the molten steel.

Although Zhang et al. have gained some valuable data and results by primary water model experiment, the defects are inevitable: the discrepancy between the structures of the shroud in Zhang's water model experiment and that of the shroud used in practice is obvious; the optimum flow rate of gas and nozzle size to generate appropriate size fine bubbles have not been obtained. So it is necessary to study furthermore and improve the technology. The flow field and pressure distribution in the shroud have been estimated in this paper by mathematical model; on the basis of the structure of shroud and the tundish used in Handan Iron and Steel Corp., flow rate of gas and nozzle size have been optimized; in order to simulate inclusion particles in the molten steel, different size polythene particles have been added to water and then effect of blowing parameters on polythene particles removal efficiency has been examined.

\section{Mathematical Model}

The mathematical model of flow in the shroud in this investigation is based on the following assumptions:

(1) the liquid steel inside the shroud is incompressible Newtonian fluid and flow fluid is steady. 
(2) the pressure at the liquid surface in the tundish is atmospheric.

Based on above assumptions, the following governing equations were solved in the mathematical model:

- the continuity equation,

- the momentum equations,

- the turbulence equation,

- the energy equation.

The parameters which were recommended by Launder and Spalding ${ }^{10)}$ were used in the mathematical model. Their values are: $C_{1}=1.44, C_{2}=1.92, \mu=0.09, \sigma_{\mathrm{k}}=1.0, \sigma_{\varepsilon}=1.3$.

Only liquid transfer inside the shroud has been investigated in this model. The distance from inlet to the sliding plane is long enough to attain a fully developed turbulent flow. The velocity at inlet depends on the height of liquid surface in ladle. Estimation for $k$ and $\varepsilon$ at inlet can be arrived at by solving expressions which were recommended by R. I. L. Guthrie. ${ }^{11)}$ A no-slip velocity boundary condition is applied, i.e., all of the velocity components are set to be zero at the wall. At the outlet, a pressure boundary condition is applied. The pressure at this level is set to be atmospheric. Calculation is carried out in this model by use of CFD software package, CFX and the structured finite difference grid is adopted.

\section{Water Model}

According to this technology, a water model fabricated from perspex with a scale of $1: 2$ has been set up, which is shown in Fig. 1. The water in the ladle which is from pump flows to tundish through the shroud. The water in the tundish is drawn out in certain flow rate by another pump, at the same time, ensuring steady water level in the tundish. The flow rate of water can be measured and controlled by rotemeter and valve. Figure 2 shows the equipment for measuring pressure in the shroud. Many tubules are been provided in the side face of the shroud with equidistance. Pressure can be measured by these tubules which communicate with the shroud. The flow rate of gas can be controlled by rotemeter.

The density of polythene particles is $1.02 \mathrm{~g} / \mathrm{cm}^{3}$, which is similar to that of water. So it suspended in the water. Polythene exhibits the contact angle of $91^{\circ}$ with water and hence is considered non-wetting. The particles sizes in this experiment were in the range of 100-424 micron in diameter which were divided into three size groups: A: 100-140 $\mu \mathrm{m}$; B: $140-283 \mu \mathrm{m}$ and C: $283-424 \mu \mathrm{m}$.

Adjusting drainage valve makes flow rate of water steady. In the condition of certain slide gate opening, adjusting water supply valve makes liquid level in the tundish steady; and then injects argon from tubule in the side face of the shroud. The mixture of polythene particles and water were injected for the period of $100 \mathrm{~s}$ and then collect polythene particles from outlet of the tundish. The collecting time is $10 \mathrm{~min}$ in this experiment; and then weighs polythene particles.

\section{Results and Discussion of Mathematical Model}

In the actual operation of continuous casting, the opening of the slide gate has to be changed from small to large in

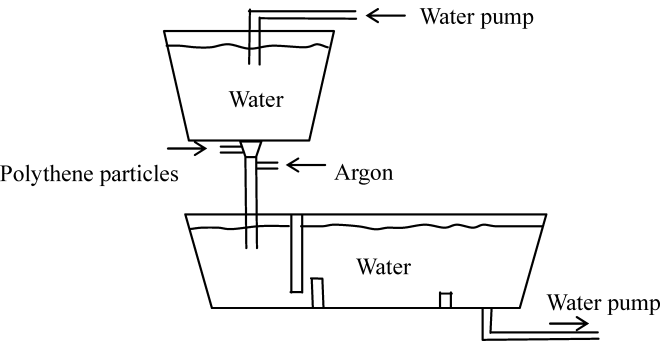

Fig. 1. Structure in water model.

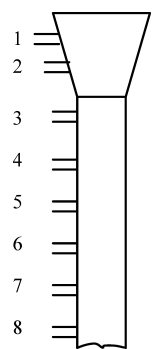

Fig. 2. Shroud structure in water model.

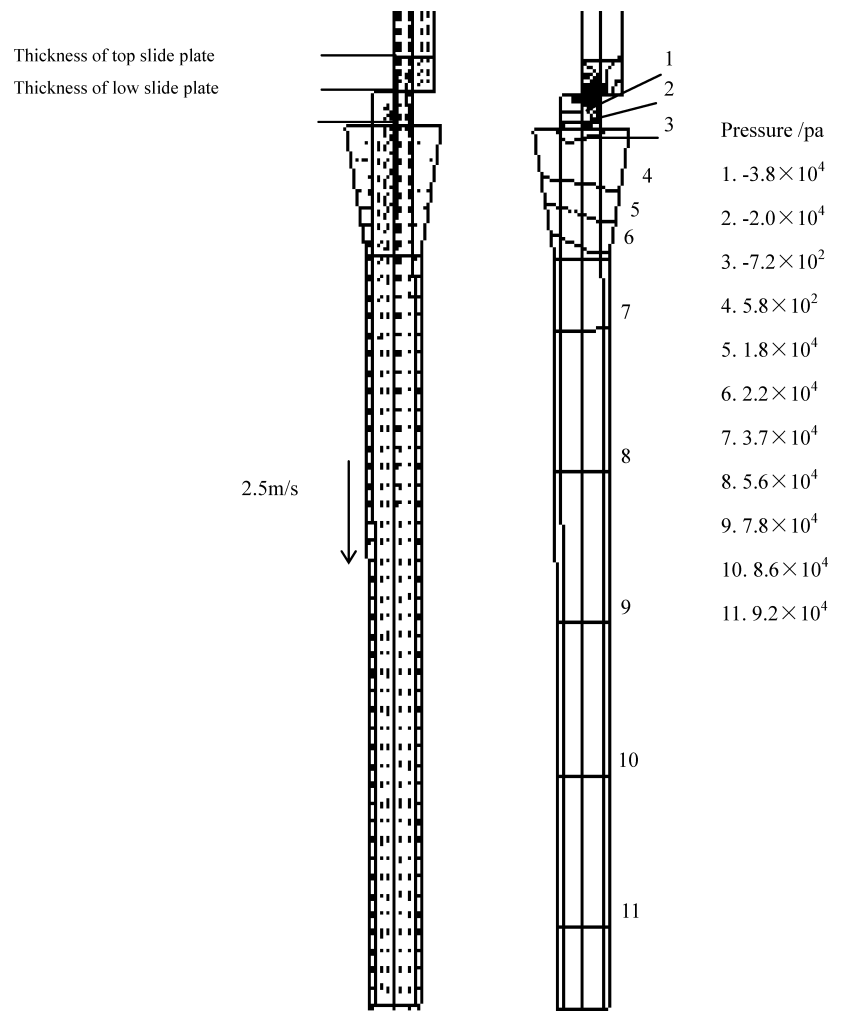

Fig. 3. Flow field and pressure distribution in shroud (at $50 \%$ opening).

order to ensure steady flow rate of the molten steel. Figure 3 is the distribution of velocity and pressure in the shroud at the opening of $50 \%$. The distribution of velocity and pressure in the shroud at the different opening of the slide gate can be founded in document. ${ }^{12)}$ From the results shown in Fig. 3, it can be seen that the mainstream direction is declining because the opening of the slide gate is not $100 \%$. The greatest velocity zone is directly at the sliding plane, in which velocity reaches to $8.0 \mathrm{~m} / \mathrm{s}$. Velocity of liquid decreases with increasing distance from the slide gate. The pressure at any position inside the shroud is below atmo- 
spheric. The longer distance from the slide gate is, the higher pressure of water inside the shroud is. The highest pressure zone is at exit of the shroud, at which pressure is atmospheric. The lowest pressure zone is directly underneath the slide gate, at which pressure is $-3.8 \times 10^{3} \mathrm{~Pa}$. It cannot be true because the pressure cannot be lower than absolute zero pressure, and the maximum pressure drop can only be atmospheric. According to the theory and experiments of fluid dynamics, ${ }^{13)}$ if the pressure in a local area of the flowing fluid falls below the vapor pressure of the liquid, there will be local boiling, and a cloud of vapor bubbles will form. This phenomenon is known as cavitation. In the vicinity of the slide gate, when the local pressure in the flowing steel is lower than the vapor pressure of liquid steel, $3 \mathrm{~Pa},{ }^{14)}$ cavitation will occur. So caivtation will occur in the upper of the part of the shroud.

\section{Results and Discussion of Water Model}

\subsection{Fine Bubbles Generation}

The positions of nozzle, flow rate of gas and nozzle size are main factor in fine bubbles size and uniform distribution in the shroud. Effect of the above parameters' variation on generated bubble have been analyzed and investigated in this paper.

\subsubsection{Effect of Position of Nozzle}

Value of velocity and pressure at different position in the shroud is different, which results in variform bubbles when injected gas from different position. So size and distribution of the generated fine bubbles by injecting argon at different position have been contrasted. Figure 4 is the generated bubbles as injecting gas from nozzle with different height. Blowing position has been changed and examined the effect of the sizes and distribution of bubbles, typical cases were selected and shown in this paper.

From Fig. 4, the number and size of bubbles in the shroud and tundish are dissimilar when gas was injected from different position. Large number of fine bubbles are generated and distributed uniformly dispersed in extended part of the shroud under intense turbulence when gas are injected from nozzle 1, which can be seen from Fig. 4(1)a, Subsequently, these bubbles flow downwards with molten steel and escape from the shroud. The bubbles entered tundish and later float up to surface of molten steel. The a, $\mathrm{b}$ and $\mathrm{c}$ in Fig. 4 represents position of nozzle, central section of shroud and tundish. It can be seen from bubbles in nozzle in Fig. 4(1), (2) and (3) that the generated bubbles are most uniform in fluid in the case o f injecting gas from nozzle 1. The blocked or pouched bubbles occur when the distance from slide gate is far. The size of bubbles in tundish is $0.5-1.0 \mathrm{~mm}$ when gas was injected from nozzle
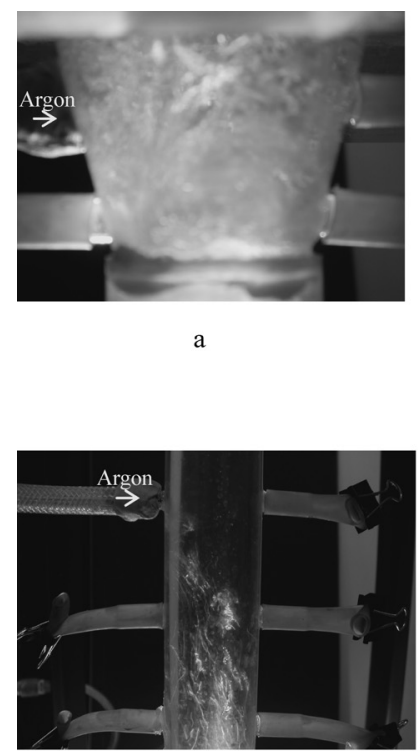

a

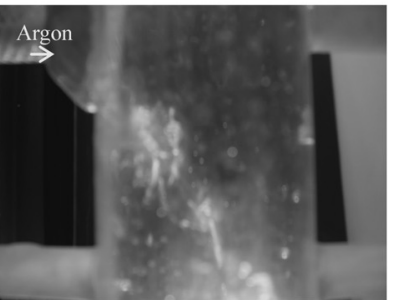

a

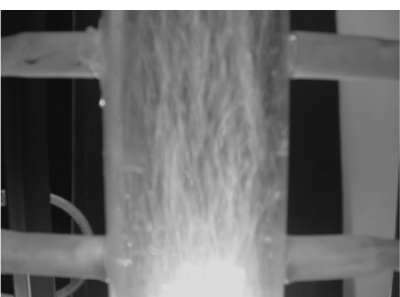

b

(1) nozzle 1 (30mm from low slide)

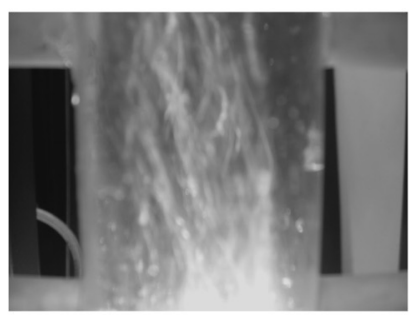

(2) nozzle 3 ( $135 \mathrm{~mm}$ from low slide

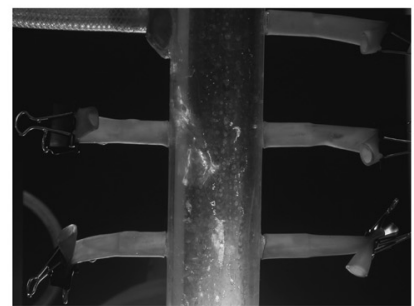

b

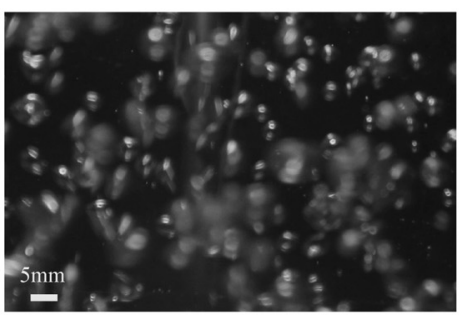

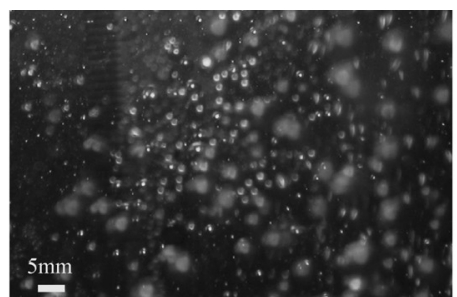

c

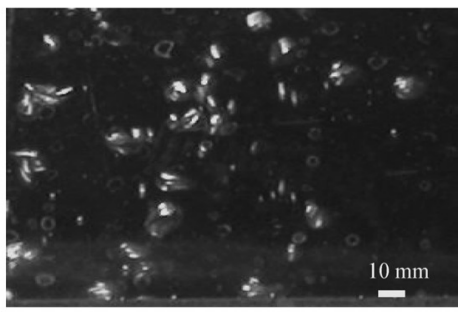

c

(3) nozzle 5 ( $255 \mathrm{~mm}$ from low slide)

Fig. 4. Shape of fine bubbles under different nozzle position (flow rate of gas: $0.4 \mathrm{~L} / \mathrm{min}$; diameter of nozzle: $5 \mathrm{~mm}$ ). 
1 , while injecting gas from nozzle 5 , most of bubbles in tundish is $4-8 \mathrm{~mm}$ and is little in number. For single bubble in liquid, in a flow with a given turbulence intensity, bubbles possess a stable size, which is defined as maximum stable bubble size $D_{\text {Bmax }}{ }^{6}$ ) Bubbles larger than $D_{\text {Bmax }}$ will be split into those smaller than $D_{\mathrm{Bmax}}$. Turbulence intensity of liquid increases when velocity of liquid increases, which leads to shear stress on bubble. Velocity of liquid is greater at higher position than at lower position. So shear stress on bubbles is greater at higher position of shroud than at lower position of the shroud which leads to generation of smaller bubbles.

\subsubsection{Effect of Flow Rate of Gas}

In order to gain bubbles with optimum size and distribution state, in water model, bubbles in shroud and tundish have been investigated when flow rate of gas changes from $0.16 \mathrm{~L} / \mathrm{min}$ to $1.6 \mathrm{~L} / \mathrm{min}$. The flow rate of gas have been defined as: $0.16 \mathrm{~L} / \mathrm{min}, 0.4 \mathrm{~L} / \mathrm{min}, 0.8 \mathrm{~L} / \mathrm{min}, 1.2 \mathrm{~L} / \mathrm{min}$ and $1.6 \mathrm{~L} / \mathrm{min}$. The results of experiment have been shown in Fig. 5 as injecting gas from nozzle 1.

Figure 5 shows that flow rate of gas have great effect on size of generated bubbles. For flow rate of $0.16 \mathrm{~L} / \mathrm{min}$, generated fine bubble size is less than $1 \mathrm{~mm}$, and larger bubble more than $4 \mathrm{~mm}$ is little. With increasing of flow rate of gas, size of generated bubbles becomes large and total number of bubbles is reduced. When flow rate of gas increases to $1.6 \mathrm{~L} / \mathrm{min}$, fine bubbles less than $1 \mathrm{~mm}$ in size almost disappear and all bubbles is in size of 4 to $6 \mathrm{~mm}$.
When flow rate of gas increases, number of the generated bubbles in unit time increases, so coalescence of bubbles is more obvious than that in low flow rate of gas. Greater number of lager bubbles result from coalescence can generate in larger flow rate of gas.

\subsubsection{Effect of Nozzle Size}

In order to investigate relationship between bubble behavior and nozzle size, gas was injected into shroud through nozzle in different size: $5 \mathrm{~mm}, 2 \mathrm{~mm}, 1.2 \mathrm{~mm}$, $0.6 \mathrm{~mm}$. Figure 6 shows experiment results of different nozzle size except for $5 \mathrm{~mm}$ because the case of $5 \mathrm{~mm}$ has been explained in section 5.1.1 and 5.1.2. Gas was injected through nozzle 1.

From Figs. 6(a)-6(c), the generated bubbles size is larger and is not uniform distribution in shroud. Small size nozzle favors generation of fine bubbles, which distributes dispersedly below shroud. The number of fine bubbles is great and most of bubbles are 1 to $2 \mathrm{~mm}$ in size. Bubbles in size of $4 \mathrm{~mm}$ are few in shroud.

\subsubsection{Optimum Blowing Parameters}

Effect of nozzle position, flow rate and nozzle size on bubble have been investigated in above section. From the results, injected gas has been split into large number of fine bubbles under condition of intense turbulence in position of nozzle 1 and distributes uniformly dispersed in shroud. So nozzle 1 is the optimum position of injecting gas; smaller flow rate and nozzle size is in favor of generating fine bub-

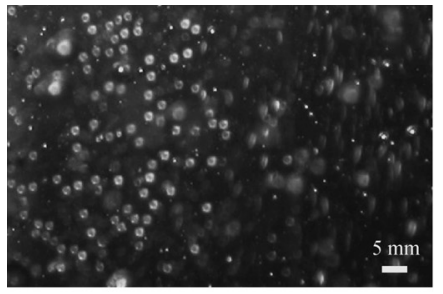

a

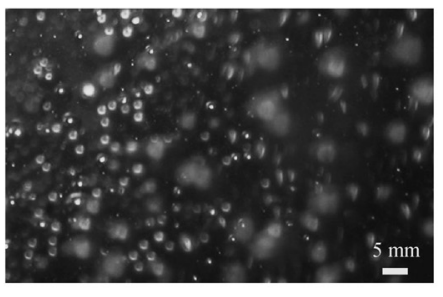

b

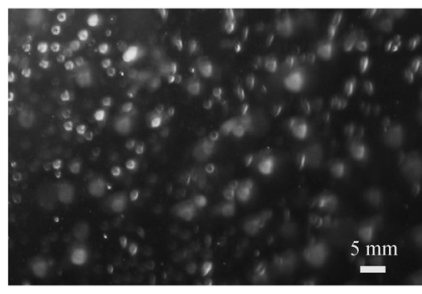

c
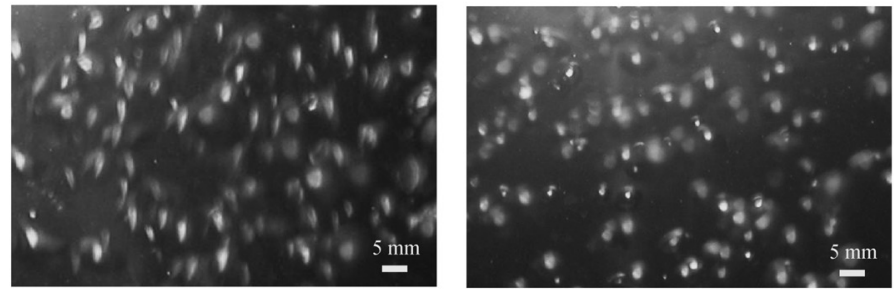

d

e

Fig. 5. Bubbles in tundish under different flow rate of gas (flow rate of gas: a, $0.16 \mathrm{~L} / \mathrm{min} ; \mathrm{b}, 0.4 \mathrm{~L} / \mathrm{min} ; \mathrm{c}, 0.8 \mathrm{~L} / \mathrm{min} ; \mathrm{d}, 1.2 \mathrm{~L} / \mathrm{min} ; \mathrm{e}, 1.6 \mathrm{~L} / \mathrm{min}$ ).

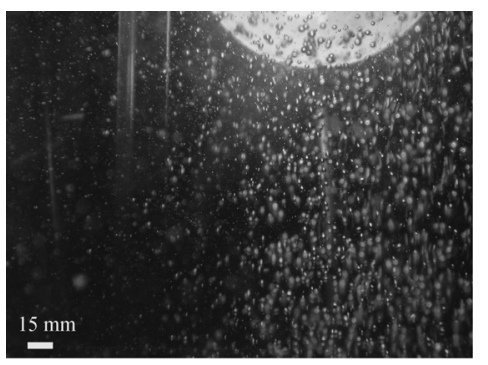

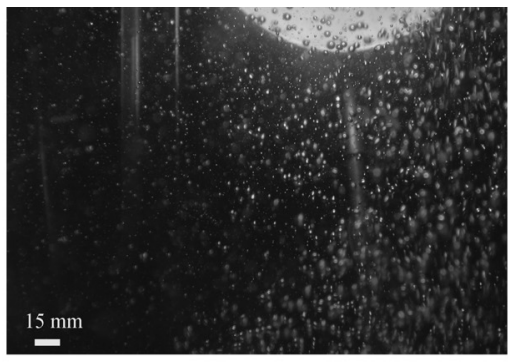

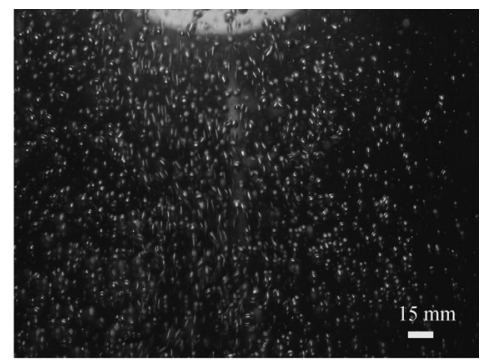

Fig. 6. Effect of nozzle size on shape of bubbles (flow rate of gas: $0.4 \mathrm{~L} / \mathrm{min}$ ). Inner diameter of nozzle: $\mathrm{a}, 2 \mathrm{~mm} ; \mathrm{b}, 1.2 \mathrm{~mm} ; 0.6 \mathrm{~mm}$. 


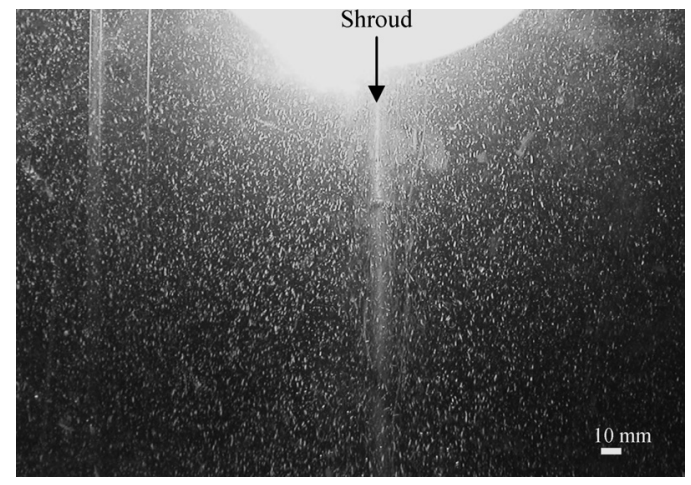

Fig. 7. Bubbles in tundish under the condition of optimum blowing parameters.

ble, so in experiment, flow rate of gas and nozzle size have been altered simultaneously. When nozzle size is $0.3 \mathrm{~mm}$ and flow rate of gas reaches to $0.08 \mathrm{~L} / \mathrm{min}$, bubble size and distribution is optimal. Figure 7 shows the optimal case: bubbles size is about 0.3 to $0.5 \mathrm{~mm}$ and distribute in tundish; larger bubbles disappears.

\subsection{Inclusion Removal Efficiency}

In order to further understand and develop the technology, particle removal efficiency has been determined under different technical condition. It is widely known that adhesion between bubble and particles depend on contact angle of particle and bubble. ${ }^{8,15)}$ If these particles is not wetting, almost all of particles adjacent to bubble adhere to it. The contact angle of $\mathrm{Al}_{2} \mathrm{O}_{3}$ and $\mathrm{SiO}_{2}$ with molten steel is $144^{\circ}$ and $115^{\circ}$ respectively, which are not wetting. So it is easy for $\mathrm{Al}_{2} \mathrm{O}_{3}$ and $\mathrm{SiO}_{2}$ to adhere to bubble. Density of polythene particles is $1.02 \mathrm{~g} / \mathrm{cm}^{3}$, which is almost equal to that of water. So polythene particles suspended in water. Furthermore, contact angle of polythene particles with water is $91^{\circ}$. It hence is considered not wetting and can adhere to bubble. In the experiment, polythene particles were used to simulate inclusion in molten steel. The used polythene particles size range is 100 to $424 \mu \mathrm{m}$, which is divided into three size group: A: 100 to $140 \mu \mathrm{m}$; B: 140 to $283 \mu \mathrm{m}$; C: 283 to $424 \mu \mathrm{m}$. Mass ratio of three groups is $5.5: 5.5: 6.5$ and mixed uniformly in sample. Total mass of sample is $17.5 \mathrm{~g}$. the particles gathered from outlet of tundish were dried, selected and weighed. To improve the measurement accuracy, the experiments were carried out for three times. Definition of particles removal efficiency is:

$$
\eta=\left(\frac{m_{0}-m_{\mathrm{t}}}{m_{0}}\right) \times 100 \%
$$

where $m_{0}$ is mass of particle added to tundish; $m_{\mathrm{t}}$ is mass of residual particle after $10 \mathrm{~min}$ under different condition; $\eta$ is particles removal efficiency.

\subsubsection{Effect of Flow Rate of Gas on Removal Efficiency}

Figure 8 is effect of flow rate of gas on removal efficiency of particle in different size group. In a word, when gas was injected from shroud, removal efficiency of different size particle is also different. Removal efficiency of particles in $\mathrm{A}$ and $\mathrm{B}$ group reduce with increasing of flow rate of gas when flow rate gas is greater than $0.2 \mathrm{~L} / \mathrm{min}$. While

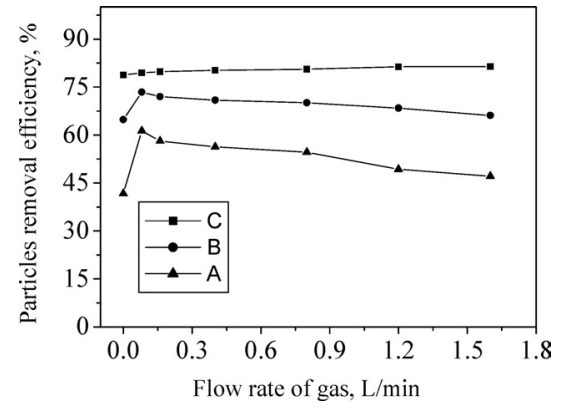

Fig. 8. Effect of flow rate of gas on removal efficiency of different size particles (flow rate of water: $3.6 \mathrm{~m}^{3} / \mathrm{h}$ ).

that of particles in $\mathrm{C}$ group have contrary tendency. The reason is that larger flow rate of gas leads to increasing of number of large bubbles and number of bubbles in size of 0.3 to $0.5 \mathrm{~mm}$ reduce, which lower removal efficiency of particles in A and B group. Size of particles in C group is 283 to $424 \mu \mathrm{m}$, which almost equal to bubble size. So removal efficiency of particles in $\mathrm{C}$ group is low. When flow rate of gas increase, the number of large bubbles increase, which is helpful to removal of particles in $\mathrm{C}$ group by adhesion. From Fig. 8, in despite of low adhesion probability, particles in $\mathrm{C}$ group have highest total removal efficiency because these particles have high velocity of flotation. So effect of flow rate of gas on removal efficiency of small particles (such as A group) is more remarkable. When flow rate of gas reduce from 1.6 to $0.16 \mathrm{~L} / \mathrm{min}$, removal efficiency of particles in A group increase from 47.1 to $61.3 \%$.

The probability of inclusion capture depends on collision probability, adhesion probability and detachment probability. The possibility of inclusion detachment from a bubble is neglected. ${ }^{4)}$ Adhesion and collision probability relate to bubble and inclusion size. The relationship between probability of inclusion capture and collision probability and adhesion probability has been shown in document. ${ }^{1)}$ The results from the document are: when bubble size is small, the total probability is higher than that in case of big bubble size. Big inclusion is easier to remove than small inclusion. ${ }^{1)}$ But inclusion smaller than $0.5 \mathrm{~mm}$ have very low speed of flotation, so the optimum bubbles size for inclusion removal is about $1 \mathrm{~mm}$. The detailed description about agglomeration and coalescence of inclusion can be obtained from the document. ${ }^{1)}$ The results in the paper are consistent with that in the above document.

It is noticed that there are no any relation between bubble size and density. In fact, polythene particles used in water model is not uniform in density. Density of some particles is larger than that of water, density of some particles is smaller than water, and density of other particles is approximately equal to water. So removal of the first type of particles is fall, while removal of the second type of particles is flotation, removal of the last type of particles suspends in water. In this way, in three types of particles, only particles suspended in water are removed by bubble flotation and each type includes different size particles. i.e. particles suspended in water also have different size. In particles suspended in water, larger particles have higher total removal probability than smaller particles. ${ }^{1)}$ Despite size, Particles suspended in water have uniform density. 


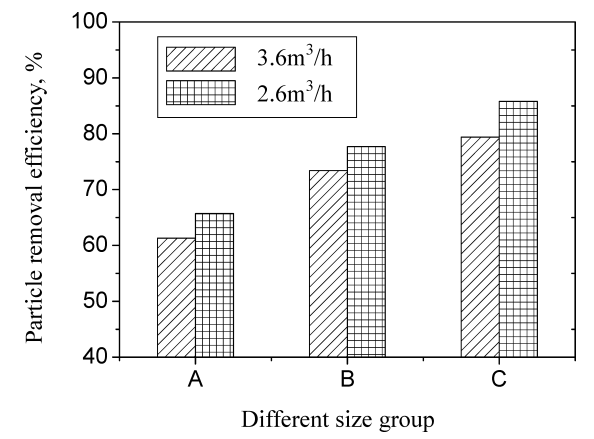

Fig. 9. Effect of casting velocity on removal efficiency of different size particle.

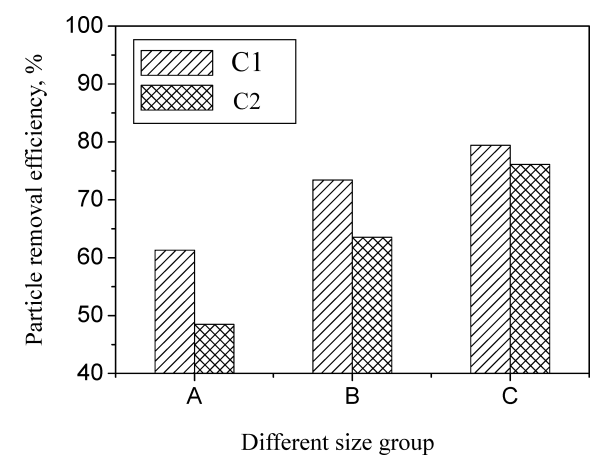

Fig. 10. Effect of amount of particle on removal efficiency (C1: A $6.5 \mathrm{~g}$, B $5.5 \mathrm{~g} \mathrm{C} 5.5 \mathrm{~g}$; C 2: A 4.5 , B $4 \mathrm{~g} \mathrm{C} 4 \mathrm{~g}$ ).

\subsubsection{Effect of Flow Rate of Water on Particles Removal Efficiency}

Flow field and residence time of molten steel in tundish is different with changement of casting velocity. Flow field and residence time have great effect on inclusion removal efficiency. Figure 9 is particles removal efficiency when flow rate of water is $3.6 \mathrm{~m}^{3} / \mathrm{h}$ and $2.6 \mathrm{~m}^{3} / \mathrm{h}$, respectively. From the result, low casting velocity favors particles removal. The reason is that residence time is longer under condition of low casting velocity, and then probability of particles flotation increases. In this way, number of bubbles occupied by each particle in unit time increases, which improve particles removal efficiency.

\subsubsection{Effect of Number of Particles}

In order to investigate effect of inclusion content on removal efficiency, different mass particles was added into water in 100 s. The results have shown in Fig. 10, when particle content is lower, removal efficiency is lower. Furthermore, this tendency is more remarkable for small size particles.

\subsubsection{Discuss of Particle Property}

Polythene particle was widely used to simulate inclusion behavior in the molten steel. Although the contact angle between polythene and water differs from the one between
$\mathrm{Al}_{2} \mathrm{O}_{3}$ and $\mathrm{SiO}_{2}$ and molten steel, So it is difficult to estimate the real phenomenon correctly. Moreover, the used polythene particles size is larger than inclusion particles in molten steel. Transfer behavior is dissimilar for different size particle, so it is difficult to describe effect of fine bubbles on inclusion removal efficiency quantitatively. It is also true that particles removal efficiency is different to real case for density of particles in water model is different to real inclusion in molten steel. However, it is not easy to find appropriate particle to simulate inclusion in molten steel. Although differences exist, in this water model, reference value exists for qualitative analysis of inclusion in the molten steel. It is not a quantitative result. So it is necessary to find appropriate particles to simulate inclusion behavior more precisely.

\section{Conclusions}

Flow field and pressure distribution in shroud have been predicted by mathematical model. Effect of flow parameters such as gas injected position, flow rate of gas and nozzle size on bubbles generation and behavior have been investigated by water model. Polythene particles were added to study the effect of flow parameters on particles removal efficiency, quantitatively.

The results show that strong turbulence intensity favors generation and distribution of fine bubbles; fine bubbles in size of $0.3-0.5 \mathrm{~mm}$ can generates in shroud and tundish by injecting gas with appropriate flow rate; superfluous gas can make bubble size sharply big; big nozzle size make against generation and distribution of fine bubbles in shroud and tundish; the extend portion of shroud is optimum position for injecting gas; appropriate flow rate of gas and nozzle size can improve greatly particles removal efficiency.

\section{REFERENCES}

1) L. F. Zhang and S. Taniguchi: Int. Mater. Rev, 45 (2000), 59.

2) H. J. Schulze: Miner. Process. Extractive Metall. Rev., 5 (1989), 43.

3) A. V. Nguyen and J. Ralton: Int. Miner. Process., 53 (1998), 225.

4) R. H. Yoon and G. H. Luttrell: Miner. Process. Extractive Metall. Rev., 5 (1989), 101.

5) L. H. Wang, H.-G. Lee and P. Hayes: ISIJ Int., 36 (1996), 7.

6) G. M. Evans, G. J. Jameson and B. W. Atkinson: Chem. Eng. Sci., 47 (1992), 3265.

7) Y. Xie and F. Oeters: ISIJ Int., 32 (1992), 66.

8) L. T. Wang, Q. Y. Zhang and S. H. Peng: ISIJ Int., 45 (2005), 331.

9) L. T. Wang, Q. Y. Zhang and C. H. Deng: ISIJ Int., 45 (2005), 1138.

10) B. E. Launder and D. B. Spalding: Comp. Meth. Appl. Mech. Eng., 3 (1974), 269.

11) R. I. L. Guthrie: Metall. Trans B, 17B (1986), 149.

12) L. T. Wang, Q. Y. Zhang and S. H. Peng: Steel Res. Int., 77 (2006), 44.

13) J. F. Douglas: Fluid Mechanics, Longman Scientific \& Technical, England, (1986), 15.

14) Y. Kawai and Y. Shiraishi: Handbook of Physico-Chemical Properties at High Temperatures, ISIJ, Tokyo, (1988), 75.

15) W. Pan, K.-I. Uemura and S. Koyama: Tetsu-to-Hagané, 78 (1992), 87. 